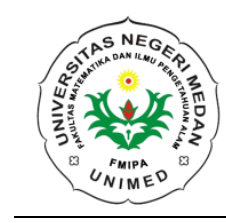

\author{
JURNAL EINSTEIN \\ Jurnal Hasil Penelitian Bindang Fisika \\ Available online http://jurnal.unimed.ac.id/2012/index.php/einsten \\ e-issn: $2407-747 x$, p-issn $2338-1981$
}

\title{
MENENTUKAN POSISI IKAN DAN KEDALAMAN DANAU TOBA DIDAERAH PARAPATKECAMATAN GIRSANG SIPANGAN BOLON KABUPATEN SIMALUNGUNPROVINSI SUMATERA UTARA DENGAN METODE SONAR
}

\author{
D.Y.Sitepu dan J.Hutahaean
}

\author{
Jurusan Fisika, Fakultas Matematika dan Ilmu Pengetahuan Alam, Universitas Negeri Medan, \\ Indonesia \\ Deborasitepu7@gmail.com \\ Diterima September 2018; Disetujui Oktober 2018; Dipublikasikan November 2018
}

\begin{abstract}
ABSTRAK
Penelitian ini bertujuan untuk mengidentifikasi posisi ikan di daerah Danau Toba kedalaman berapa ikan ditemukan menggunakan Garmin Aquamap 80xs, untuk mengetahui kedalaman agar dapat membuat tanda wilayah wisata bagi para perenang guna keselamatan pariwisatawan. Berdasarkan analisis nilai pemetaan penelitian ini menggunakan Metode peneliti menetukan lokasi penelitian, peneliti mempersiapkan alat yang digunakan terlebih dahulu menghubungkan alat-alat yang diperlukan, teknik pengambilan data peneliti menggunakan sensor dengan sonar tersebut diletakkan di samping kapal sehingga terkena air dan menentukan lintasan , analisis data dan interprestasi data peneliti melakukan dari hasil lapangan tiap titik lintasan maka peneliti terlebih dahulu mentransfer data dari Gps ke labtop dengan menggunakan BaseCame Map. Hasil penelitian menunjukkan bahwa daerah pantai bebas Danau Toba terdapat populasi ikan yang paling banyak pada posisi E98 56.105' N2 40.069' dari kedalaman 221.9m terdapat posisi ikan dalam kedalaman $100 \mathrm{~m}$ pada suhu 26,4 , pada titik ke-7, dan zona aman renang bagi para wisatawan menjelaskan bahwa pemetaan didaerah pantai bebas memiliki kedalaman 4 meter sampai 10,3 meter dari jarak 2 meter dari pinggir pantai pada bujur 40.000 lintang 56.000, layak untuk berenang. Berdasarkan hasil penelitian ini daerah pantai bebas dihimbau kepada Dinas Pariwisata supaya membuat batas-batas zona aman renang karena jarak 10 meter dari pinggir pantai kedalaman Danau toba tidak teratur atau kedalaman Danau tidak dangkal.
\end{abstract}

Kata Kunci : Sensor Sonar, Posisi Ikan, Zona Aman Renang

\section{PENDAHULUAN}

Danau Toba merupakan Danau terbesar di Indonesia yang terletak di Provinsi Sumatera Utara. Danau Toba banyak dimanfaatkan oleh masyarakat untuk kegiatan budidaya ikan di KerambaJaring Apung (KJA), pertanian, Pariwisata, dan pemukiman penduduk. Namun saat ini penangkapan ikan, bagi para pemancing atau para nelayan ikan di daerah Danau Toba kesulitan untuk mendapatkan ikan, diakibatkan ikan cendrung menurun, sehingga para nelayan sulit menemukan ikan.

Penelitian tentang penangkapan ikan sebelumnnya telah dilakukan oleh M.Zainal Abidin (2015) menggunakan metode sensor sonar yang dilakukan di Laboratorium Teknik Elektro Universitas Lampung, menunjukkan bahwa hasil penelitian sensor terhadap ikan sesuai dengan yang diinginkan, maka motor akan berputar, namun jika sensor belum mendeteksi kedatangan ikan maka sensor melakukan pendeteksian 
kembali.Danau Toba terkenal dengan keindahan Danaunya, dimana objek wisata sangat menarik perhatian parawisatawan. Dimana informasi kedalaman Danau Toba bagi parawisatawan sangatlah penting demi keselamatan baik untuk anak-anak, bahkan orang dewasa. Dimana pengelola wisata harus mengetahui kedalaman dan membuat batas-batas zona aman untuk berenang guna keselamatan parawisatawan (Lenny,S.2005).

Sonar merupakan salah satu aplikasi sistem pengindraan jauh untuk pencitraan bawah Laut maupun Danau. Sonar adalah suatu sistem yang terdiri dari transduser dengan arah miring, beserta unit perkembangannya yang dapat digunakan untuk memberi informasi citra bawah Laut atau Danau. Prinsip kerja sonar adalah sebagai berikut; pertama, echosounder mengemisikan gelombang suara berfrekuensi tinggi. Gelombang suara akan merambat dalam air. Jika mengenai objek yaitu ikan atau benda lainnya, maka gelombang suara tersebut akan dipantulkan kembali ke monitor, sinyal pantulan akan diterima oleh hidrofon dan ditampilkan oleh display yang menggambarkan karateristik objek dibawah air.Dari hal tersebut sensor sonar sangat berperan penting untuk mengidentifikasi posisi ikan dan zona aman renang, dimana sistem sensor sonar dapat mengidentifikasi pergerakan, dan hasil pencitraan dibawah air dapat sisajikan dalam bentu dua dimensi (Wijonarko,W,dkk.2016).

\section{METODE PENLITIAN}

\section{Alat Dan Bahan}

Alat yang digunakan adalah Aquamap 80xs, GMR 18 Xhdradome, Plastik Transom Mount transduser/airmar TM, Power Kabel, Card Memory, Labtob, Kompas.

Bahan yang digunakan adalah areal perairan Danau Toba yang diambil beberapa lintasan. Lokasi Danau Toba di Parapat Kecamatan Girsang Sipangan Bolon Kabupaten Simalungun Provinsi Sumatera Utara.

\section{PROSEDUR PENELITIAN}

Metode yang digunakan pada penelitian ini adalah kajian dilakukan diaeral Danau Toba. Prosedur penelitian yang dilakukan adalah sebagai berikut;
1. Menghubungkan antena ke monitor, kemudian menghubungkan kabel power pada monitor, dan transducer juga dihubungkan pada layar.

2. Menghidupkan monitor/ layar SVGA dan membuka tampilan menu, kemudian membuka menu peta dan peneliti dapat mengatur peta kemudian menavigasikan, jejak, simbol, titik lintasan.

3. Menentukan posisi daerah survei dengan menggunakan GPS, lalu menentukan pengukuran pada tempat yang akan diteliti.

4. Membuka menu pengukuran, pilih kompas, kemudian pilih perjalanan, pilih menu info nav, pilih jejak/track, pilih record track aktifkan.

5. Pengambilan data menggunakan Garmin Aquamap 80xs pada setiap lintasan yang ditentukan.

6. Mentransfer data dari GPS ke labtop menggunakan BaceCame, dengan cara terlebih dahulu nyalakan GPS hubungkan GPS ke labtop menggunakan kabel data yaitu mini USB 5 pin.

7. Menjalankan program BaseCame, klik new route, klik ditempat yang ingin melakukan survey, klik device dan send to device pilih memory card yang akan digunakan di Aquamap, klik ok

8. Pilih menu transfer data, klik ya

9. Mengolah data yang diperoleh dari layar SVGA menggunakan software sehingga memproleh 2D sampai 3D sepanjang lintasan yang ditentukan

10. Setelah memindahkan data, peneliti mengolah data dengan mikrosoft excel, dan untuk pemodelan 3D dilakukan dengan menggunakan program inversi dengan prangkat surver 9 .

11. Melakukan analisis dan intervrestasi data

12. Membedakan nilai berdasarkan warna untuk melihat struktur kedalaman zona aman renang dan posisi ikan pada setiap titik dari model 3D sepanjang lintasan. 


\section{HASIL DAN PEMBAHASAN \\ Deskripsi Data Posisi Ikan}

Daerah penelitian dilakukan mulai dari daerah batu gantung dengan posisi E98 ${ }^{\circ} 55.400^{\prime}$ $\mathrm{N} 2^{\circ} 40.600^{\prime}$ menuju ke pinggir pantai bebas dengan posisi E98 $56.200^{\prime}$ N2 ${ }^{\circ} 40.100^{\prime}$ dan menelusuri dari pinggir pantai sampai ketengah danau dengan posisi E98 56.000' $\mathrm{N} 2^{\circ} 40.000^{\prime}$. Data sensor sonar yang didapat dalam melakukan penelitian ini terdiri dari 5 lintasan, pengamatan sensor sonar berupa lokasi yaitu Bujur dan Lintang. Data yang diperoleh dari penelitian akan diubah ke konversi koordinat online yaitu daerah posisi ikan dapat dilihat pada gambar 1. Dari ke 5 lintasan diperoleh 11 titik posisi ikan yaitu:

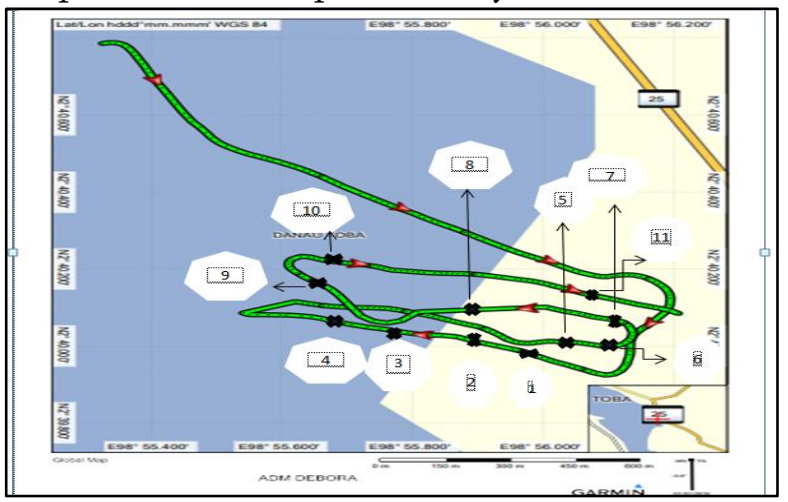

Gambar 1. Gambar Posisi Ikan

Tabel 1 Posisi ikan terprediksi

\begin{tabular}{|c|c|c|c|c|c|}
\hline $\begin{array}{l}\mathrm{N} \\
\mathrm{o}\end{array}$ & Kdlm & $\begin{array}{l}\text { p.ik } \\
\text { an }\end{array}$ & Posisi & ${ }^{\circ} \mathrm{C}$ & \\
\hline 1 & $\begin{array}{c}111.5 \\
\mathrm{~m}\end{array}$ & $\begin{array}{l}30 \\
\mathrm{~m}\end{array}$ & $\begin{array}{l}\text { E98 } 55.801^{\prime} \\
\text { N2 }^{\circ} 40.086^{\prime}\end{array}$ & $26,4^{\circ} \mathrm{C}$ & \\
\hline 2 & $\begin{array}{c}105.9 \\
\mathrm{~m}\end{array}$ & $50 \mathrm{~m}$ & $\begin{array}{c}\text { E98 }^{\circ} 55.878^{\prime} \\
\text { N2 }^{\circ} 40.058^{\prime}\end{array}$ & $26,4^{\circ} \mathrm{C}$ & \\
\hline 3 & $\begin{array}{c}164.6 \\
\mathrm{~m}\end{array}$ & $50 \mathrm{~m}$ & $\begin{array}{c}\mathrm{E}^{\circ} 8^{\circ} 66.047^{\prime} \\
\mathrm{N}^{\circ} 40.009^{\prime}\end{array}$ & $26,4^{\circ} \mathrm{C}$ & \\
\hline 4 & $\begin{array}{c}118.2 \\
\mathrm{~m}\end{array}$ & $60 \mathrm{~m}$ & $\begin{array}{c}\text { E98 } 56.094^{\prime} \\
\text { N2³9.999' }^{\circ}\end{array}$ & $26,4^{\circ} \mathrm{C}$ & \\
\hline 5 & $\begin{array}{c}47.0 \\
\mathrm{~m}\end{array}$ & $\begin{array}{c}49,5 \\
\mathrm{~m}\end{array}$ & $\begin{array}{l}\text { E98 }^{\circ} 56.136^{\prime} \\
\text { N2 }^{\circ} 40.025^{\prime}\end{array}$ & $26,4^{\circ} \mathrm{C}$ & \\
\hline 6 & $\begin{array}{c}202.3 \\
\mathrm{~m} \\
\end{array}$ & $\begin{array}{c}31,6 \\
\mathrm{~m}\end{array}$ & $\begin{array}{l}\text { E98 }^{\circ} 56.116^{\prime} \\
\text { N2 }^{\circ} 40.065^{\prime}\end{array}$ & $26,4^{\circ} \mathrm{C}$ & \\
\hline 7 & $\begin{array}{c}221.9 \\
\mathrm{~m}\end{array}$ & $\begin{array}{c}100 \\
\mathrm{~m}\end{array}$ & $\begin{array}{l}\text { E98 }^{\circ} 66.105^{\prime} \\
\text { N2 }^{\circ} 40.069^{\prime}\end{array}$ & $26,4^{\circ} \mathrm{C}$ & \\
\hline 8 & $\begin{array}{c}575.0 \\
\mathrm{~m} \\
\end{array}$ & $40 \mathrm{~m}$ & $\begin{array}{l}\text { E98 }^{\circ} 55.628^{\prime} \\
\text { N2 }^{\circ} 40.186^{\prime} \\
\end{array}$ & $26,5^{\circ} \mathrm{C}$ & 2 \\
\hline 9 & $\begin{array}{c}586.3 \\
\mathrm{~m}\end{array}$ & $50 \mathrm{~m}$ & $\begin{array}{l}\text { E98 }^{\circ} 55.631^{\prime} \\
\text { N2 }^{\circ} 40.183^{\prime}\end{array}$ & $26,5^{\circ} \mathrm{C}$ & 2 \\
\hline
\end{tabular}

\begin{tabular}{|c|c|c|c|c|c|}
\hline 10 & $\begin{array}{c}273.2 \\
\mathrm{~m}\end{array}$ & $\begin{array}{c}92,3 \\
\mathrm{~m}\end{array}$ & $\begin{array}{c}\mathrm{E}^{\circ} 8^{\circ} 55.657^{\prime} \\
\mathrm{N}^{\circ} 40.226^{\prime}\end{array}$ & $26,6^{\circ} \mathrm{C}$ & \pm \\
8 & & 8 \\
\hline 11 & $\begin{array}{c}138.7 \\
\mathrm{~m}\end{array}$ & $32 \mathrm{~m}$ & $\begin{array}{c}\mathrm{E}^{\circ} 8^{\circ} 56.129^{\prime} \\
\mathrm{N}^{\circ} 40.113^{\prime}\end{array}$ & $26,7^{\circ} \mathrm{C}$ & 2 \\
& & & \\
\hline
\end{tabular}

Dimana populasi ikan yang lebih banyak terdapat pada posisi E98 ${ }^{\circ} 56.105^{\prime} \mathrm{N}^{\circ}{ }^{\circ} 40.069^{\prime}$, pada suhu $26,4{ }^{\circ} \mathrm{C}$, rentang dari kedalaman $221,9 \mathrm{~m}$ terdapat posisi ikan dalam $100 \mathrm{~m}$ dapat dilihat pada gambar 2

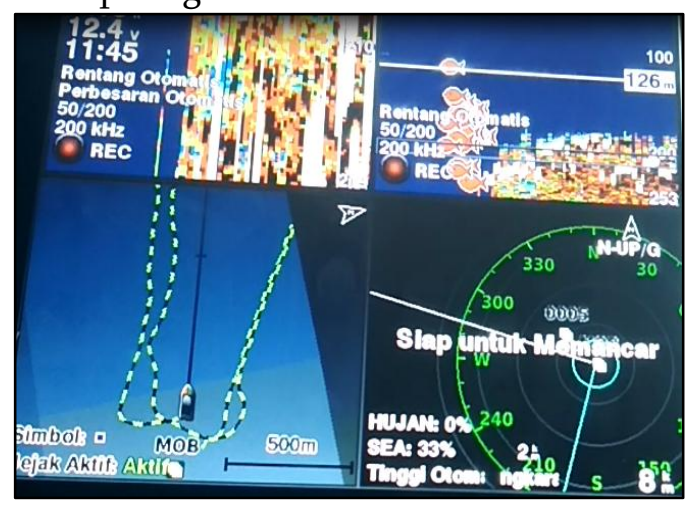

Gambar 2. Jumlah Ikan Yang Lebih Banyak

\section{Deskripsi Data Topografi}

Kondisi topografi kedalaman dasar Danau pada zona aman renang dan lintasan kapal, dapat dilihat pada gambar 3

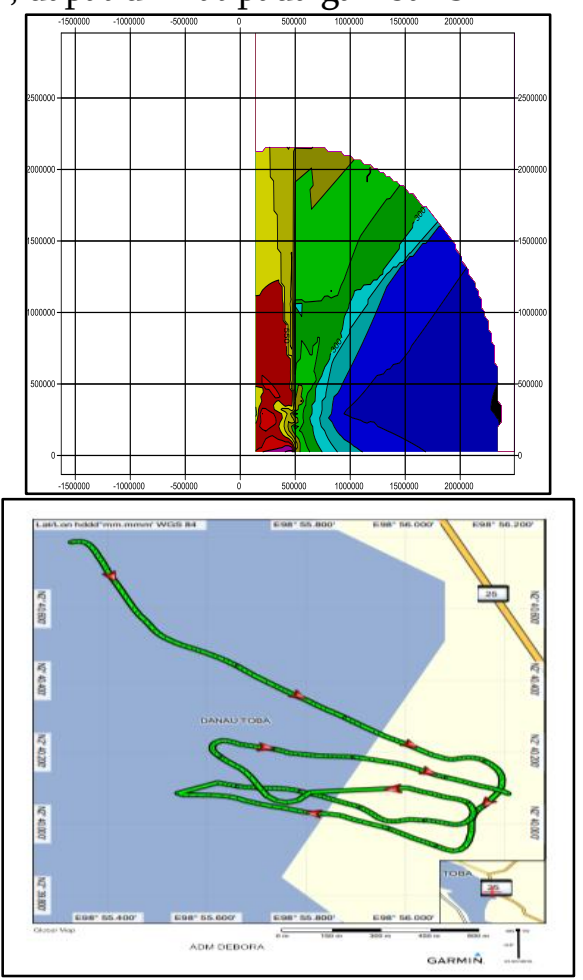

Gambar3. Topografi Kedalaman Zona Renang Danau Dan Lintasan Kapal 
Setelah dilakukan pengambilan data dengan menggunakan alat sensor sonar (Aquamap 80xs). Lintasan yang telah ditentukan kemudian dilakukan pengunduhan data maka didapatkan hasil tentang menentukan posisi ikan dan zona aman renang dari tiap-tiap titik. Menggunakan alat sensor sonar Aquamap 80xs dilakukan diperairan Danau Toba tepatnnya didaerah pantai bebas Parapat Kecamatan Girsang Sipangan Bolon Kabupaten Simalungun.Dari 5 lintasan diperoleh 1437 titik pengukuran bujur, lintang dan kedalaman dapat dilihat pada Lampiran 5 tabel hasil bujur, lintang, kedalaman Danau Toba. Kualitas perekaman sensor sonar kedalaman zona aman renang sangat ditentukan oleh kondisi lapangan dalam mengirim dan memantulkan kembali sinyal yang dipancarkan. Hasil perekaman sensor sonar Aquamap 80xs ini mendapat target, kedalaman zona aman renang. Didaerah pantai lepas memiliki kedalaman 2 meter sampai 10,3 meter pada jarak 2 meter dari pinggir pantai pada bujur E98 ${ }^{\circ} 56.000$ ', lintang N2 $40.000^{\prime}$ pada jarak dari pinggir pantai pada bujur E98 $55.045^{\prime}$ lintang $\mathrm{N} 2^{\circ} 40.085^{\prime}$ memiliki kedalaman $596.5 \mathrm{~m}$, jadi zona aman renang di daerah pantai bebas 2,2 meter sampai 10,3 meter pada jarak 2 meter dari pinggir pantai pada bujur E98 ${ }^{\circ} 56,000^{\prime}$ lintang N2 $40.000^{\prime}$. Pantai bebas terletak pada posisi bujur E98 56,160 ' lintang N2 ${ }^{\circ} 40.053^{\prime}$ terdapat kedalaman 10,3 meter, pada posisi bujur E98 ${ }^{\circ} 56,153$ ' lintang N2 ${ }^{\circ} 40.047^{\prime}$ terdapat kedalaman 3,6 meter, pada posisi bujur E98 56,152'lintang N240.046' terdapat kedalaman 2,2 meter. Jadi daerah zona aman renang di daerah pantai bebas terdapat kedalaman 2,2 meter sampai 10,3 meter, terdapat pada jarak 9 meter dari pinggir pantai ke tengah pantai, penampang kontur kedalaman danau toba dapat dilihat pada Gambar 4.

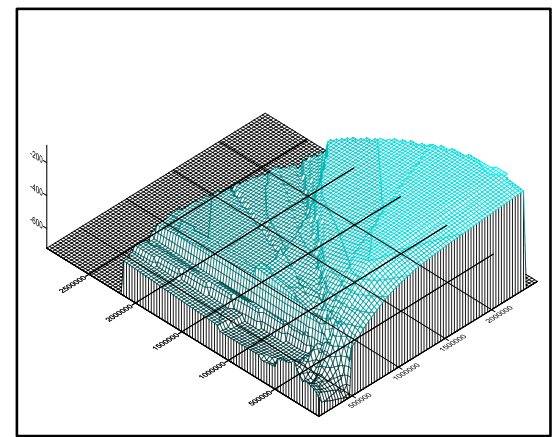

Gambar 4. Kontur Kedalaman Danau Toba

Gambar 4. Kontur Kedalaman Danau Toba menjelaskan bahwa hasil pemetaan didaerah pantai bebas memiliki kedalaman 4 meter sampai 10,3 meter dari jarak 2 meter dari pinggir pantani pada bujur 40.000 lintang 56.000. Pada jarak dari pinggir pantai pada bujur 40.085 lintang 55.045 memiliki kedalaman 596.5, jadi zona aman renang didaerah pantai bebas memiliki kedalaman 4 meter sampai 10,3 meter dari jarak 2 meter dari pinggir pantai sampai 10 meter arah ke tengah Danau pada bujur 40.000 lintang 56.000 .

\section{Kesimpulan}

\section{KESIMPULAN DAN SARAN}

Dari hasil pengolahan, analisis dan interprestasi data pada peneliti dapat diambil kesimpulan sebagai berikut:

1. Berdasarkan nilai interprestasi terdapat 5 lintasan. Saat penelitian posisi ikan dapat terprediksi 11 titik, pada titik yang terprediksi yang pertama dalam kedalaman $111.5 \mathrm{~m}$, posisi E98 ${ }^{\circ} 55.801^{\prime}$ $\mathrm{N} 2^{\circ} 40.086$ ', suhu di dalam danau $26.4^{\circ} \mathrm{C}$, titik ke-II kedalaman 105.9 meter, dan seterusnya,Dimana populasi ikan yang lebih banyak terdapat pada posisi E98 ${ }^{\circ} 56.105^{\prime} \quad \mathrm{N}{ }^{\circ} 40.069^{\prime}$ dalam kedalaman 221.9 meter pada suhu 26,4 ${ }^{\circ} \mathrm{C}$, yaitu pada titik ke-7, jadi menurut dari terperature, jenis ikan tersebut yang terprediksi yaitu ikan muzair dan ikan pora-pora.

2. 2. Hasil pemetaan Kontur Kedalaman Danau Toba menjelaskan bahwa hasil pemetaan didaerah pantai bebas memiliki kedalaman 4 meter sampai 10,3 meter dari jarak 2 meter dari pinggir pantani pada bujur 40.000 lintang 
56.000. Pada jarak dari pinggir pantai pada bujur 40.085 lintang 55.045 memiliki kedalaman 596.5, jadi zona aman renang didaerah pantai bebas memiliki kedalaman 4 meter sampai 10,3 meter dari jarak 2 meter dari pinggir pantai sampai 10 meter arah ke tengah Saran Danau pada bjur 40.000 lintang 56.000 .

Dari hasil penelitian yang telah diperoleh, maka saran yang dibuat untuk para penulis selanjutnya yaitu:

1. Melakukan penelitian berlanjut di daerah yang sama, dengan memperbanyak titik pengamatan dan memperluas lokasi yang diteliti, sehingga nantinya diperoleh nilai yang akurat.

2. Pemerintah daerah membuat batas zona aman untuk berenang pada jarak 10 meter dari pinggir pantai, karena daerah disekitar pantai parapat bukan daerah yang aman untuk berenang.

3. Pada penelitian selanjutnya dilakukan dengan jarak minimal $75 \mathrm{~m}$ pada perputaran kapal

\section{DAFTAR PUSTAKA}

Abidin,Z.M.,(2015),Pembuatan Prototipe Bagan

Penangkapan Ikan Otomatis

Menggunakan Sensor Sonar,

Skripsi.Lampung:Laboratorium

Terpadu Teknik Elektro,Universitas

Lampung

Bangsa,C.P.,Sugito.,Zuhrawati.,Daud,R.,Asmillia

,N.,Azhar.,(2015),Pengaruh

Peningkatan Suhu Terhadap Jumlah

Eritrosit Ikan Nila(Oreochromis

niloticus),Jurnal Medika

Veterinaria.Vol. 9 No 12015

Banowati,E.,(2013),

Geografi

Sosial,Ombak,Medan

Barus,T.A.,(2004),Pengantar Limnologi Studi

Tentang Ekosistem Sungai dan

Danau.Jurusan Biologi Fakultas MIPA USU.Medan

Barus,T.A.,(2007),Keanekaragaman Hayati

Ekosistem Danau Toba dan Upaya Pelestariannya.Pidato Pengukuhan Jabatan Guru Besar Tetap Bidang Ilmu

$$
\begin{aligned}
& \text { Limnologi Pada Fakultas } \\
& \text { MIPA.USU.,(5-9) }
\end{aligned}
$$

Buku Panduan Garmin., GMR 18/24 GMR 18

$\mathrm{H} / 24 \quad \mathrm{HD}$, Radome Installation

Instructions.com

Hani,S.,(2009),Proteksi Arus Lebih Dengan Menggunakan Sensor Arc

706elc.Jurnal TeknologiVol 2(2) 167175

Helligs,S.J.,(1767),Radar Algemene Beginselen En Toeposing, N.V,Philips,Nederland

Lubis,M.Z.,Pujuyati,S.,danWulandari,P.d.,(2013)

,Persamaan Sonar (Sonar Equation) Untuk Dunia Kelautan (For Marine)

Lubis, Z.M.,dan Anurogo,W.,(2017),Identifikasi

Profil Dasar LautMenggunakan

Instrumen Side Scan Sonar Dengan

Motode Beam Partern,JurnalVol 10(1)

(87-96)

Manik,M.H.,(2014),Teknologi Akustik Bawah

Air Solusi Data Perikanan Laut

Indonesia,JurnalVol 1(3) 181-186

Musa,K.,(1988),Geologi Asia

Tenggara.Universitas Of Houston

Rohmawati,I.T.,(2014),Tugas Akustik Kelautan

Contoh Kasus Penggunaan

Sonar.Fakultas Perikanan dan Ilmu Kelautan:Universitas Brawijaya

Sani,A.R.,(2017),Fisika Terapan Smart,Tira Smart,Tanggerang

Sari,S.P.,(2009),Deteksi dan Interpretasi Target

Di Dasar Laut Menggunakan

Instrumen Side Scan Sonar,

Skripsi,Bogor:Fakultas Perikanan dan

Ilmu Kelautan,IPB

Silitonga,P.M.,(2011),Metodologi Penelitian

Pendidikan, FIPA.UNIMED

Stiawan,I.,(2016),Simulasi Model Sensor Sonar Untuk Keperluan Sistem Navigasi Robot Mobile,Jurnal.Vol 2(1) 11-14

Tarigan,P.A.,Yunasfi.,Suryanti,A,(2014),Struktur Komunitas Ikan di Sungai Naborsahan Danau Toba Sumatera Utara,Fakultas Pertanian USU

Wijonarko,W.W.,Sasmito,B.,Nugraha,A.L,(2016

), Kajian Pemodelan Dasar Laut Menggunakan Side Scan Sonar dan Singlebeam

Echosounder,Jurnal.Geodesi Undip Vol 5(2) 169-171 